\begin{tabular}{c} 
Brazilian Journal \\
of Chemical \\
Engineering \\
\hline
\end{tabular}

ISSN 0104-6632

Printed in Brazil www.abeq.org.br/bjche

Vol. 32, No. 02, pp. 501 - 508, April - June, 2015

dx.doi.org/10.1590/0104-6632.20150322s00003048

\title{
OPTIMIZATION OF PRODUCTION OF 5-HYDROXYMETHYLFURFURAL FROM GLUCOSE IN A WATER: ACETONE BIPHASIC SYSTEM
}

\author{
A. D. M. Mendonça ${ }^{1}$, P. M. Siqueira ${ }^{1 *}$, M. M. V. M. Souza ${ }^{2}$ and N. Pereira Jr. ${ }^{2}$ \\ ${ }^{1}$ Federal Institute of Education, Science and Technology of Rio de Janeiro, (IFRJ), \\ Rua Lúcio Tavares, 1045, 26530-060, Nilópolis/RJ, Brazil. \\ ${ }^{2}$ School of Chemistry, Federal University of Rio de Janeiro, (UFRJ), Centro de Tecnologia, \\ Bloco E, 21941-909, Rio de Janeiro/RJ, Brazil. \\ "E-mail: priscila.siqueira@ifrj.edu.br; \\ andreza.memelli@gmail.com; mmattos@eq.ufrj.br; nei@eq.ufrj.br
}

(Submitted: October 21, 2013 ; Revised: May 28, 2014 ; Accepted: June 6, 2014)

\begin{abstract}
Hydroxymethylfurfural (HMF) is considered to be an important building block for biorefineries and has a high potential for the production of chemicals and fuels. Production of HMF from glucose was studied using phosphoric acid as catalyst, in a water:acetone system with volume ratio of 1:2 and $\mathrm{NaCl}$. An experimental design was applied to examine the influence of temperature, time and concentration of catalyst on the HMF yield. HMF yields of more than $50 \%$ were obtained when using $200{ }^{\circ} \mathrm{C}, 8.4 \mathrm{~min}$ and $0.8 \%$ of catalyst. The temperature is the main factor influencing the HMF yield.

Keywords: 5-hydroxymethylfurfural; Glucose; Acetone; Design of experiments.
\end{abstract}

\section{INTRODUCTION}

There is a growing interest in fuels and chemicals from renewable sources and furan compounds are an alternative platform for biorefinery processes (Román-Leshkov and Dumesic, 2009; Huang et al., 2010). This versatile family of compounds may result in derivatives which can replace fossil fuels as the source of traditional chemical intermediates for the production of polyesters, polyamides and polyurethanes (Moreau et al., 2004).

One of the most attractive furan compounds is 5hydroxymethylfurfural (HMF), which occurs naturally as a product of thermal degradation of sugars and nowadays is considered to be a biorefinery build- ing block, or a key compound for the development of an advanced biorefinery (Rasrendra et al., 2010). From this compound, 2,5-dimethylfuran (Román-Leshkov et al., 2007), esters of levulinic acid and HMF ethers (Yang. et al., 2012, Peng et al., 2011, Peng et al., 2012) can be obtained, for possible use in Otto cycle or diesel engines, besides furan dicarboxylic acid (FDCA), applied in the production of polyesters (Ribeiro and Schuchardt, 2003).

The main route for obtaining HMF is the dehydration of monosaccharides, like glucose and fructose, catalyzed by acids. However, many other products can be obtained from sugars in acidic aqueous medium, such as furfural, levulinic acid, formic acid, lactic acid, mannose and glycolaldehyde (Antal et

*To whom correspondence should be addressed 
al., 1990, Lecomte et al., 2002, Moliner et al., 2010, Watanabe et al., 2005). Other important point to note is that yields from fructose are not reproduced by using glucose in aqueous medium, due to the higher ring stability that causes a higher rate of enolization of fructose (ketose) in relation to glucose (aldose), which is an important step to facilitate the dehydration reaction (Pidko et al., 2010, Zakrzewska et al., 2011). Zakrzewska (2011) reported several studies using ionic liquids for conversion of hexoses, Simeonov and coworkers (2013) studied integrated chemo-enzymatic systems for glucose conversion and the yields were higher than obtained with aqueous medium, but the trend to lower yields with glucose that with fructose was also observed. Biphasic systems can improve the yields because HMF is continuous extracted from the aqueous phase to the organic phase, avoiding rehydration and condensation reactions, and the use of solvent with low boiling point is desirable to facilitate the product separation. Water:acetone mixtures have been used as reaction medium for HMF production to promote the rearrangement of fructose to the furanoid form (Biker et al., 2003). Roman-Leshkov and Dumesic (2009) tested a biphasic system water (saturated with $\mathrm{NaCl}$ ):acetone at $150{ }^{\circ} \mathrm{C}$ for $35 \mathrm{~min}$, with $\mathrm{HCl}$ as catalyst and obtained $62 \%$ of fructose conversion with $79 \%$ of $\mathrm{HMF}$ selectivity, however, the system was not tested for glucose. Acetone can also be used as solvent for HMF extraction after reaction (Zhang et al., 2010). Phosphoric acid was used as catalyst in aqueous media and the maximum glucose conversion was approximately $60 \%$ at $220{ }^{\circ} \mathrm{C}$ for $5 \mathrm{~min}$, with HMF yield of 9.6\% (Daorattanachai et al., 2012).

In general, most of the studies use a dilute solution of glucose, resulting in low product concentrations, increasing the cost of separation and purification. Despite their efforts, the industrial production of HMF is not yet a reality. It is still necessary to find a process that is highly selective with high isolated yields of HMF so that the final price is competitive. According to Putten et al. (2013), the use of glucose or cellulose and starch for the production of HMF is still a challenge because the more extreme conditions of conversion are also possible degradation conditions for HMF, a barrier that must be overcome to make the process economically more favorable. The purpose of this study was to evaluate different reaction conditions (temperature, time and catalyst concentration) in acetone/water systems saturated with $\mathrm{NaCl}$, using $\mathrm{H}_{3} \mathrm{PO}_{4}$ as catalyst and concentrated solutions of glucose for HMF produc- tion. For this, response surface methodology (RSM) was applied in order to obtain an optimum condition for HMF production from glucose.

\section{EXPERIMENTAL}

\section{Dehydration Procedure}

For the tests 1-17, $100 \mathrm{~mL}$ of glucose solution $\left(250 \mathrm{~g} . \mathrm{L}^{-1}\right), 200 \mathrm{~mL}$ of acetone and $30 \mathrm{~g}$ of sodium chloride were used, and the temperature, time and catalyst concentration $\left(\mathrm{H}_{3} \mathrm{PO}_{4}\right)$ were varied in accordance with the experimental design matrix. All experiments were performed in a stainless steel reactor $(450 \mathrm{~mL})$ with agitation at $350 \mathrm{rpm}$. The salt promotes the phase separation water:acetone by saturation of the aqueous phase. The pressure was the result of system dynamics (20-21 bar). After cooling the reactor the two phases were separated using a separatory funnel and the products were analyzed by high performance liquid chromatography (HPLC) using a Shimadzu Prominence instrument with Aminex HPX-87H column at $55^{\circ} \mathrm{C}$, an injection loop of $20 \mu \mathrm{L}$ and $5 \mathrm{mM}$ sulphuric acid at $0.8 \mathrm{~mL} \cdot \mathrm{min}^{-1}$ as the mobile phase. Glucose residue was detected by refractive index (RID-10A) and HMF by the UV detector at $210 \mathrm{~nm}$ (SPD-20AV). Acetone was recovered using a rotary evaporator at $30^{\circ} \mathrm{C}$ and reused.

Glucose conversion (X), HMF yield (Y) and HMF selectivity (S) were calculated according to Eqs. (1)-(3):

$\mathrm{X}=\frac{\text { moles of glucose reacted }}{\text { moles of glucose initial }} \times 100$

$\mathrm{Y}=\frac{\text { moles of HMF produced }}{\text { moles of glucose initial }} \times 100$

$S=\frac{Y}{X} \times 100$

Three tests to verify the autocatalysis possibility as reported by Ranoux et al (2013) and to evaluate the influence of each system component were performed. First an aqueous solution of glucose was heated from room temperature to $200{ }^{\circ} \mathrm{C}$, removing aliquots from $120{ }^{\circ} \mathrm{C}$ every twenty degrees. In the second, added acetone $1: 1$ and $30 \mathrm{~g}$ of $\mathrm{NaCl}$ and, last, using glucose solution with $1 \%$ of phosphoric acid, with the same sampling procedure. 


\section{Experimental Design}

The central composite design (CCD) was used to evaluate the effects of three independent variables or factors: temperature $\left(\mathrm{x}_{1}\right)$, time $\left(\mathrm{x}_{2}\right)$ and concentration of catalyst $\left(\mathrm{x}_{3}\right)$. The design consisted of 8 factorial points $\left(2 n=2^{3}=8\right), 6$ axial points and 3 central points, totaling 17 trials. The glucose conversion $(\mathrm{X})$, the HMF yield $(\mathrm{Y})$ and the HMF selectivity (S) are the dependent variables. The studied levels for each factor are described in Table 1. STATISTICA version 6 was utilized to estimate the approach of RSM with CCD.

Table 1: The range and levels of the independent variables for CCD.

\begin{tabular}{|l|c|c|c|c|c|}
\hline \multirow{2}{*}{ Factors } & \multicolumn{5}{|c|}{ Levels } \\
\cline { 2 - 6 } & $\boldsymbol{- \alpha}$ & $\mathbf{- 1}$ & $\mathbf{0}$ & $+\mathbf{1}$ & $+\boldsymbol{\alpha}$ \\
\hline Temperature $\left({ }^{\circ} \mathrm{C}\right)-\mathrm{x}_{1}$ & 183.2 & 190 & 200 & 210 & 216.8 \\
$\mathrm{H}_{3} \mathrm{PO}_{4}(\% \mathrm{v} / \mathrm{v})-\mathrm{x}_{2}$ & 0.33 & 0.5 & 0.75 & 1.0 & 1.17 \\
Time $(\mathrm{min})-\mathrm{x}_{3}$ & 1.6 & 3.0 & 5.0 & 7.0 & 8.4 \\
\hline
\end{tabular}

\section{RESULTS AND DISCUSSION}

Glucose can form true oligosaccharides that still contain reactive reducing groups, resulting in a greater risk of cross-polymerisation with reactive intermediates and HMF (Rosatella et al., 2011), coupled with the fact that the stability of the ring limits the yield in aqueous media. In many reactions the formation of black solid residues was observed, especially in tests conducted at high temperatures, as reported in Shi et al. (2013). The high concentration of glucose could favor the reverse reaction to form oligosaccharides that can be dehydrated and form char. For the tests 117 , the conversions were greater than $89 \%$ (Table 2). Yield values ranged from $19 \%$ to $49 \%$, and the selectivity from $21 \%$ to $52 \%$; the worst results were obtained in test 9 , which was carried out at the lowest temperature, $183^{\circ} \mathrm{C}$. The effect of temperature on yield is observed when comparing this test with the ones at the central point (tests 15-17), where the conditions were the same except that the temperature was $200{ }^{\circ} \mathrm{C}$ : the HMF yield obtained was almost double that of test 9. In addition to HMF, levulinic acid, formic acid and furfural have been identified as products in a few tests.

The statistical analysis was performed in four steps: significance test of the factors, graphical analysis of the residuals, ANOVA and application of F test to subsequently trace the response surface. The magnitude of the effects of the factors temperature, time and catalyst concentration on the response variables is shown in the diagrams of Figure 1, which presents
Pareto charts for glucose conversion (a), HMF yield (b) and selectivity (c). For the conversion, the temperature was the most influential factor, which is consistent with the natural tendency of glucose to be converted with increasing temperature, and all of the other factors were significant. On the other hand, the major influence on the yield was the catalyst concentration, for which the Pareto diagram indicates a reduction in the initial concentration of acid. The time factor was statistically significant for the conversion factor, and not significant for yield and selectivity, for the range of values studied. Since the yield is the main parameter of the study, all subsequent analysis will be directed to evaluate the optimization of this factor.

Table 2: Experimental design matrix and results for CCD.

\begin{tabular}{|c|c|c|c|c|c|c|}
\hline & \multicolumn{3}{|c|}{ Factors } & \multicolumn{3}{c|}{$\begin{array}{c}\text { Response } \\
\text { variables }\end{array}$} \\
\hline Test & $\begin{array}{c}\text { Temperature } \\
\left(\mathbf{(}^{\circ} \mathbf{C}\right) \\
\end{array}$ & $\begin{array}{c}\text { Time } \\
(\mathbf{m i n})\end{array}$ & $\begin{array}{c}\mathbf{\%}_{\mathbf{3}} \mathbf{H}_{\mathbf{4}} \\
\mathbf{\mathbf { x }}_{\mathbf{1}}\end{array}$ & $\begin{array}{c}\mathbf{X} \\
\mathbf{( \% )}\end{array}$ & $\begin{array}{c}\mathbf{Y} \\
\mathbf{( \% )}\end{array}$ & $\begin{array}{c}\mathbf{S} \\
\mathbf{( \% )}\end{array}$ \\
\hline 1 & -1 & -1 & -1 & 90 & 22 & 24 \\
2 & -1 & -1 & +1 & 92 & 31 & 34 \\
3 & -1 & +1 & -1 & 91 & 29 & 32 \\
4 & -1 & +1 & +1 & 92 & 34 & 37 \\
5 & +1 & -1 & -1 & 96 & 42 & 43 \\
6 & +1 & -1 & +1 & 99 & 33 & 33 \\
7 & +1 & +1 & -1 & 98 & 36 & 37 \\
8 & +1 & +1 & +1 & 100 & 24 & 24 \\
9 & 0 & 0 & -1.68 & 90 & 30 & 33 \\
10 & 0 & 0 & +1.68 & 97 & 32 & 33 \\
11 & 0 & -1.68 & 0 & 90 & 40 & 44 \\
12 & 0 & +1.68 & 0 & 95 & 49 & 52 \\
13 & -1.68 & 0 & 0 & 89 & 19 & 21 \\
14 & +1.68 & 0 & 0 & 100 & 40 & 40 \\
15 & 0 & 0 & 0 & 92 & 40 & 43 \\
16 & 0 & 0 & 0 & 91 & 42 & 46 \\
17 & 0 & 0 & 0 & 91 & 40 & 44 \\
\hline
\end{tabular}

$\mathrm{X}=$ Conversion, $\mathrm{S}=$ Selectivity and $\mathrm{Y}=$ Yield (molar)

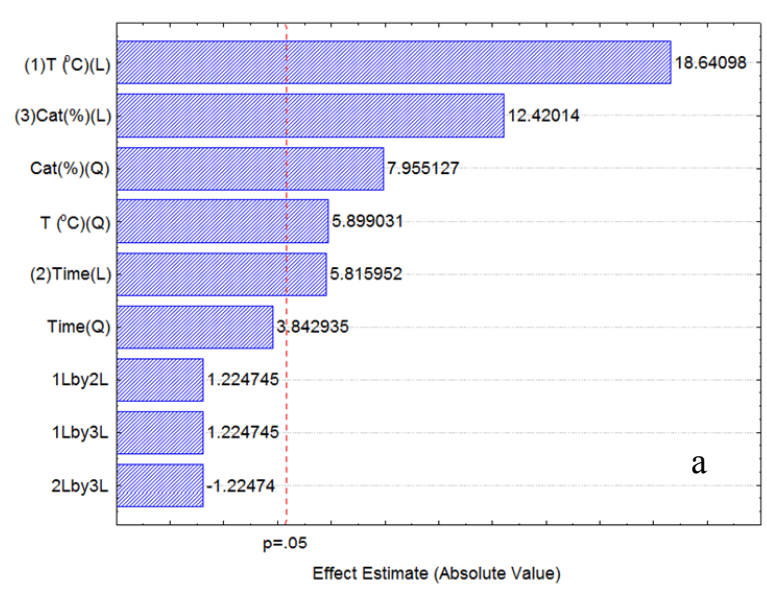



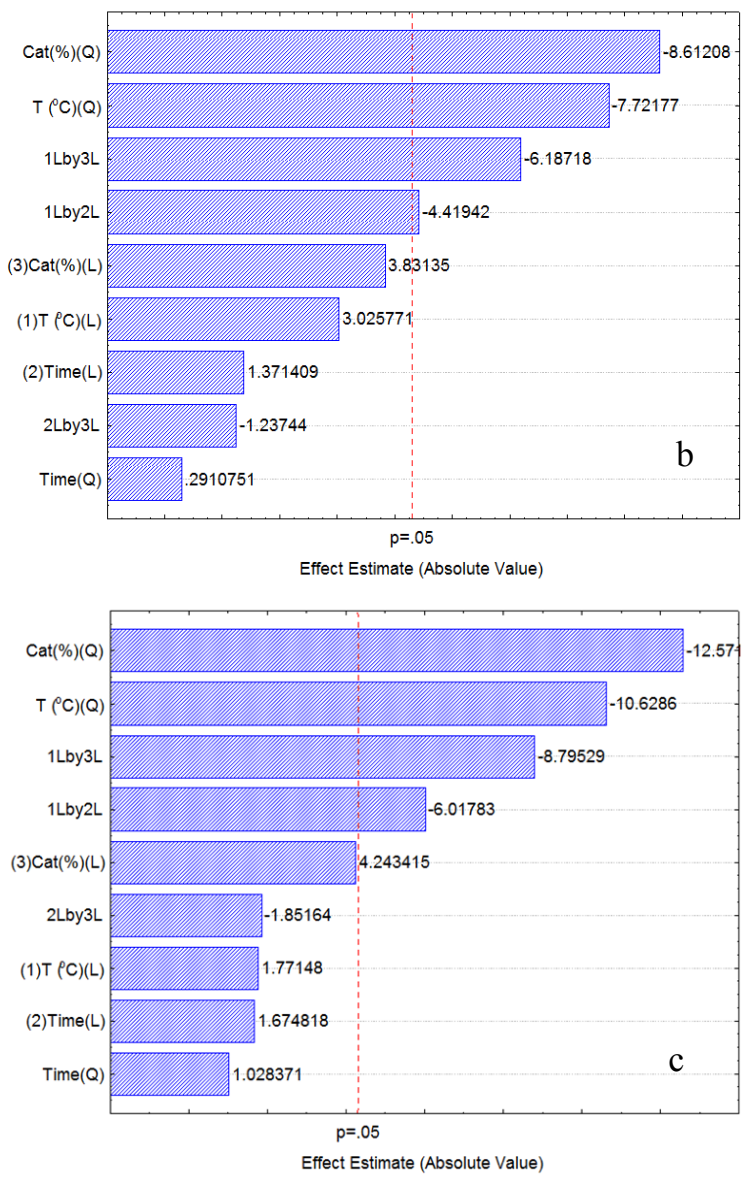

Figure 1: Pareto charts of CCD. Glucose dehydration for glucose conversion (a) HMF yield (b) and selectivity (c).

The graphical analysis of the residuals was used to assess the normality of the data, which is indicated in Figure 2a. The expected behavior for a normal sample is observed in the graph, for which the points approximate a straight line. Once verified the normality of the data, other tests can be performed in order to assess the statistical model generated by the program. One important analysis is shown in Figure $2 \mathrm{~b}$, comparing the values predicted versus values observed, in which the deviation from the straight line through the origin is small and the points show a linear trend, indicative of model fit.

Table 3 summarizes the regression analysis for HMF yield. Analysis of variance (ANOVA) was applied to test the mathematical modeling with $\alpha=0.05$ (level of significance) and is presented in a simplified form. The $\mathrm{F}$ test was used to verify that the change of the independent variable had a significant influence on the variation of the dependent variable; if so, the calculated value of $F\left(F_{\text {calc }}\right)$ is greater than the tabulated $\mathrm{F}$ ( $\left.\mathrm{F}_{\text {value }}\right)$. This hypothesis was verified for the three response variables, indicating that the model generated adequately described the phenomenon. The $\mathrm{F}$ test was used to verify that the change of the independent variable had a significant influence on the variation of the dependent variable; since $F_{\text {calc }}=17.3074$ is greater than $F_{\text {value }}=3.63$, this hypothesis was verified, indicating that the model generated describes adequately the phenomenon.
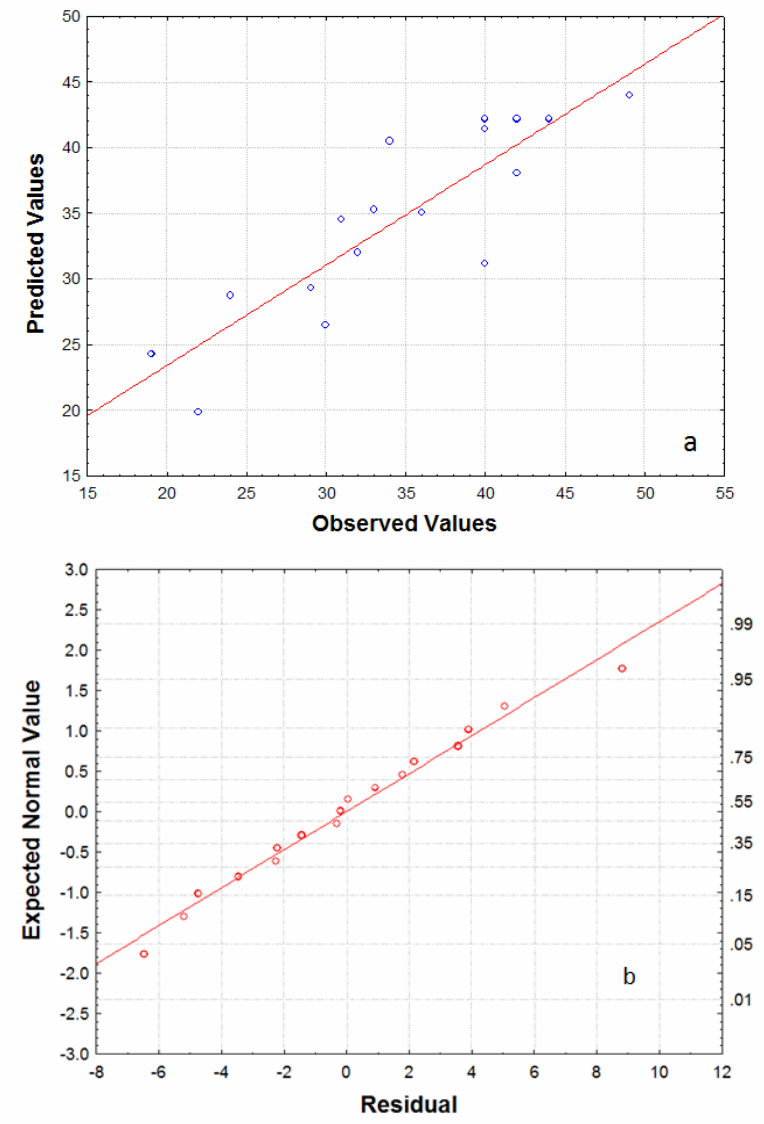

Figure 2: Graphical analysis of residuals. a) comparison of normal probability to residuals; b) Observed vs. predicted values for HMF yield.

Table 3: ANOVA of glucose conversion, HMF yield and selectivity.

\begin{tabular}{|l|r|c|c|c|c|}
\hline \multicolumn{1}{|c|}{ Mode } & $\begin{array}{c}\text { Sum of } \\
\text { squares }\end{array}$ & $\begin{array}{c}\text { Degrees of } \\
\text { freedom }\end{array}$ & $\begin{array}{c}\text { Mean } \\
\text { Squares }\end{array}$ & $\mathbf{F}_{\text {Value }}$ & $\mathbf{F}_{\text {Table }}$ \\
\hline HMF Yield & & & & & \\
Regression & 875.75 & 9 & 925.207 & 17.3074 & $F_{0.05}=3.63$ \\
Residual & 255.286 & 7 & 53.4573 & & \\
Total & 1131.036 & 16 & & & \\
\hline
\end{tabular}

The model Equation (Eq. (4)) was obtained for the HMF yield, in which the variables $\mathrm{x}_{1}$ and $\mathrm{x}_{3}$ are the temperature and catalyst concentration, respectively, and $\mathrm{Y}$ is the HMF yield. The quadratic fit of the model should satisfy $\mathrm{R}^{2}$ greater than 0.75 featuring 
an acceptable degree of agreement between the predicted and the observed values. For the response variable in question the $\mathrm{R}^{2}$ obtained was 0.75165 and the lack of fit with $p=0.099531$, greater than 0.05 , therefore not significant and is within of significance level established. The equation is obtained for the coded values of the variables.

$$
\begin{aligned}
Y= & 42.428+1.638 x_{1}-4.651\left(x_{1}\right)^{2}+2.074 x_{3} \\
& -5.181\left(x_{3}\right)-4.375 x_{1} x_{3}
\end{aligned}
$$

The model generates the response surface of Figure 3 , in which the relation between the HMF yield and the significant response variables, temperature and catalyst concentration, is shown graphically. For this, the time at the central point, 5 min, was set. Despite the borderline fit of the model, it is possible to verify the advantage of modeling the data showing clearly that the HMF yield is optimized for the system studied. This result is consistent because at higher temperatures, the yield decreases due to the occurrence of side reactions, and at higher catalyst concentrations the same effect occurs.

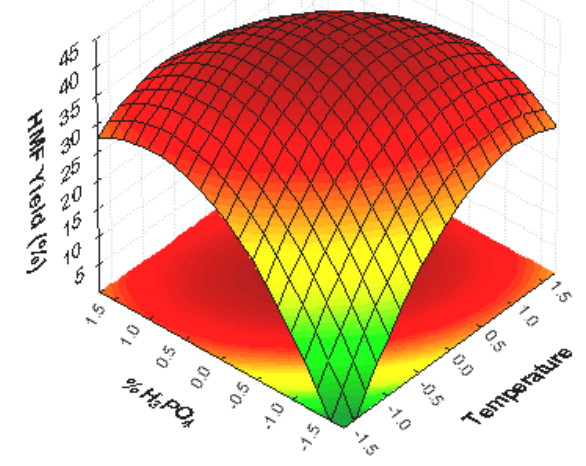

Figure 3: Response surface for HMF yield based on temperature and catalyst concentration.

\section{Effect of Biphasic System}

To evaluate the effect of the two-phase system on the HMF yield and the possibility that formic and levulinic acids promote dehydration of glucose without catalyst, three tests were performed and yields are shown in Figure 4. It was observed that only at $200{ }^{\circ} \mathrm{C}$ were significant yields obtained for the three systems. Ranoux et al. (2013) reported a 19\% conversion of glucose to HMF to $195{ }^{\circ} \mathrm{C}$ with $38 \%$ selectivity using only water. As shown in Figure 5, approximately $60 \%$ conversion was reached at $200{ }^{\circ} \mathrm{C}$ for the system water-glucose. The most probable hypothesis is that the use of the closed and agitated reactor contributed to a higher rate of mass transfer and thus increased the conversion of glucose. However, it had a negative effect on the stability of the HMF yield leading to only $0.4 \%$ in this condition. By adding the catalyst, as expected, conversion increased considerably and this trend was also observed for the yield, yet in the experiment with acetone increases to $25.3 \%$. Therefore, there is overwhelming evidence that the addition of a solvent to form a second phase that takes up HMF is critical to achieve high yields at higher temperatures.

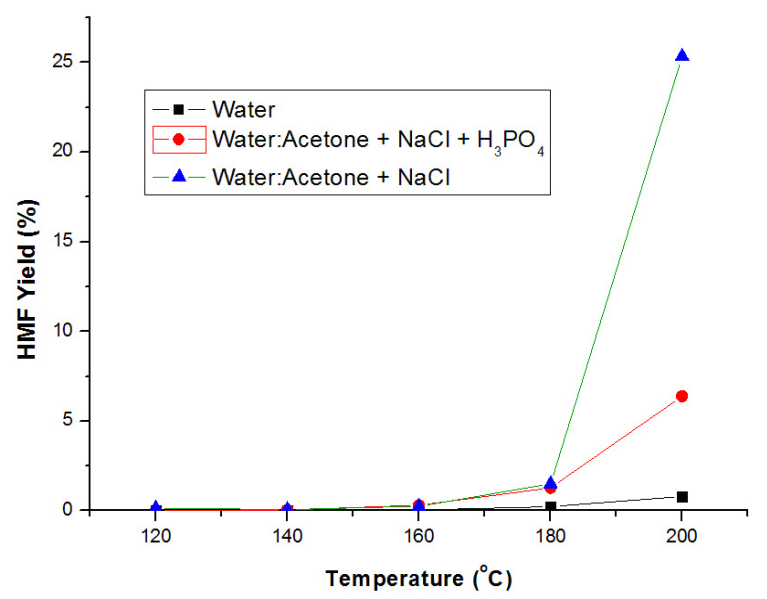

Figure 4: HMF molar yields at different temperatures. Reaction conditions: glucose solution 250 g. $\mathrm{L}^{-1}$ for all systems, phosphoric acid $1 \%(\mathrm{v} / \mathrm{v})$ when present and acetone:água 1:1 for the biphasic systems (HMF not isolated).

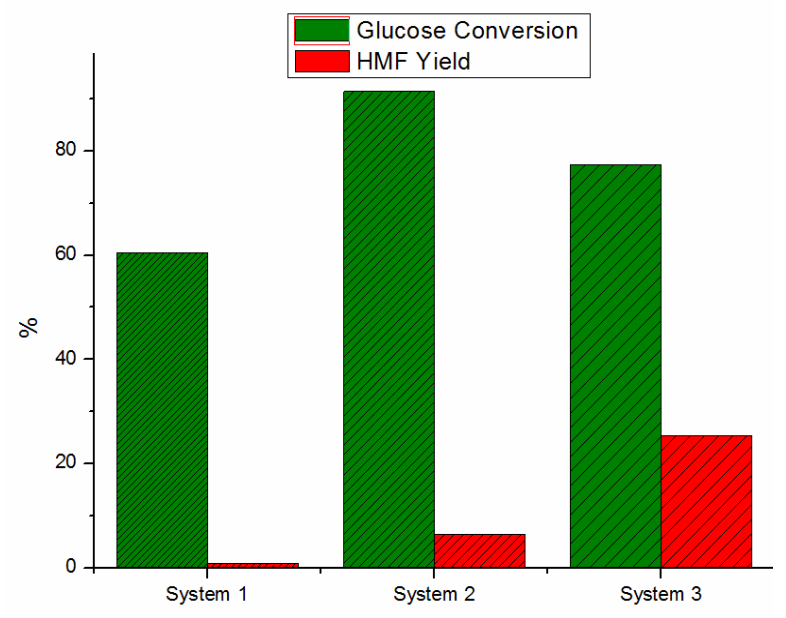

Figure 5: HMF yields and conversions at $200{ }^{\circ} \mathrm{C}$ for reactions in systems 1 (water), 2 (water:acetone + $\mathrm{NaCl}$ ) and 3 (water:acetone $+\mathrm{NaCl}+\mathrm{H}_{3} \mathrm{PO}_{4}$ ). 
The formation of formic acid, levulinic acid, furfural and HMF is shown in Figure 6 for the different temperatures tested for the system glucose, water and phosphoric acid. The results corroborate the hypothesis of HMF rehydration due to the high concentration of formic acid formed. Qi et al. (2008) observed that the fructose conversion and HMF yield improved with an increase in acetone concentration in the acetone-water mixtures attributed to a conformational change of fructose to the furanoid form in the presence of acetone, and to the suppression of HMF dehydration. The mechanism of glucose dehydration is still unclear for this mixture. In this study, small amounts of fructose were detected as product, but were insufficient to state that isomerization had occurred. Shi et al. (2013) reached a $45.2 \%$ yield of $\mathrm{HMF}$ in a biphasic system using water:tetrahydrofuran (THF) 1:10, $\mathrm{NaHSO}_{4}$ and
$\mathrm{ZnSO}_{4}$ as a catalyst and $0.2 \mathrm{~g}$ of glucose in $44 \mathrm{~mL}$ of solvent. However, the authors employed THF as the major solvent, which does have some disadvantages, such as high cost and environmental effects. A slightly higher yield (58\%) was obtained by Caes et al. (2013) in a system with $\mathrm{N}, \mathrm{N}$-dimethylacetamide (ionic liquid), $\mathrm{CrCl}_{2}$ and $10 \%$ glucose by weight.

Table 4 shows a comparison between HMF yields and initial concentrations of glucose using biphasic systems. McNeff et al. (2010) used an initial glucose concentration, time and temperature similar to those used in this study. Nikolla et al. (2011) obtained a yield similar to that obtained in this work, however, using an inorganic acid and a solid catalyst. However, HMF yields from glucose remain low when compared to fructose, as noted by Putten et al. (2013) in their recent review.

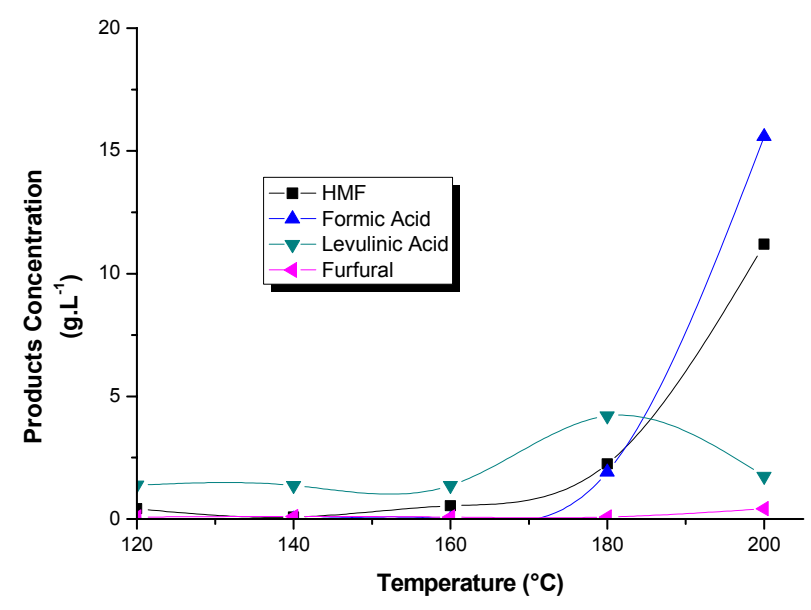

Figure 6: Product concentration versus temperature, using $1 \% \mathrm{H}_{3} \mathrm{PO}_{4}(\mathrm{v} / \mathrm{v})$ and initial glucose solution.

Table 4: HMF yields from glucose obtained in two-phase systems.

\begin{tabular}{|c|c|c|c|c|c|c|c|c|c|}
\hline $\begin{array}{c}\text { Initial Glucose } \\
\text { Concentration } \\
(\text { wt \%) }\end{array}$ & $\begin{array}{l}\text { Biphasic } \\
\text { System }\end{array}$ & Catalyst & $\begin{array}{l}\text { Catalyst } \\
\text { loading }\end{array}$ & $\begin{array}{c}\text { Temperature } \\
\left({ }^{\circ} \mathrm{C}\right)\end{array}$ & $\begin{array}{l}\text { Time } \\
(\mathrm{min})\end{array}$ & $\begin{array}{l}\mathbf{X} \\
\%\end{array}$ & $\begin{array}{l}\mathbf{Y} \\
\%\end{array}$ & $\begin{array}{l}\mathrm{S} \\
\%\end{array}$ & Reference \\
\hline $23 \%$ & Water:n-butanol & $\mathrm{TiO}_{2}$ & Fixed bed & 200 & 3 & - & 13 & - & $\begin{array}{l}\text { McNeff et al. } \\
\text { (2010) }\end{array}$ \\
\hline $10 \%$ & $\begin{array}{c}\text { Water } \\
(26 \% \mathrm{NaCl}): \mathrm{THF}\end{array}$ & Ti- $\beta$-Zeolite $/ \mathrm{HCl}$ & $\mathrm{pH}=10.5 \mathrm{~mol} \% \mathrm{Ti}$ & 180 & 105 & 76 & 53 & 70 & $\begin{array}{l}\text { Nikolla et al. } \\
\text { (2011) }\end{array}$ \\
\hline $10 \%$ & $\begin{array}{c}\text { Water } \\
(26 \% \mathrm{NaCl}): \text { n-butanol }\end{array}$ & Sn- $\beta$-Zeolite/HCl & $\mathrm{pH}=10.5 \mathrm{~mol} \% \mathrm{Sn}$ & 160 & 90 & 75 & 41 & 55 & $\begin{array}{l}\text { Nikolla et al. } \\
\text { (2011) }\end{array}$ \\
\hline $25 \%$ & $\begin{array}{c}\text { Water } \\
(30 \% \mathrm{NaCl}) \text { :acetone }\end{array}$ & $\mathrm{H}_{3} \mathrm{PO}_{4}$ & $0.8 \%(\mathrm{v} / \mathrm{v})$ & 200 & 8.4 & 95 & 49 & 52 & This study \\
\hline
\end{tabular}

$\mathrm{X}=$ Conversion, $\mathrm{S}=$ Selectivity and $\mathrm{Y}=$ Yield 


\section{CONCLUSIONS}

The analysis of the response surface for the variable yield, keeping the time constant at 5 minutes, demonstrated that the system was otimized, considering the inlet variables: temperature $\left(183.2\right.$ to $\left.216.8^{\circ} \mathrm{C}\right)$ and catalyst ( 0.33 to $1.17 \%)$. The water:acetone system studied was able to convert glucose into 5-hydroxymethylfufural, using an aprotic solvent with low boiling point, enabling a less energy-intensive recovery of the solvent. The use of a biphasic system with acetone and $\mathrm{NaCl}$ to extract the $\mathrm{HMF}$ promoted an increase in the reaction yield compared to the aqueous system because HMF migrates preferentially into the organic phase, avoiding its rehydration. The statistical analysis showed that the HMF yield is optimized within the range of factors used. The best result obtained was an approximately 50\% $\mathrm{HMF}$ yield at $200{ }^{\circ} \mathrm{C}$, in 8.4 minutes and $0.75 \%$ of catalyst, which is appreciable when considering the low reaction time, ease of solvent recovery and low toxicity of the reagents; however, HMF was not totally isolated from the reaction medium. The relativity low cost of the reaction system (catalyst and solvent), when compared to the cost of ionic liquids or other aprotic solvents, makes this system even more attractive.

\section{ACKNOWLEDGMENTS}

Special thanks to Luiz Claudio for the support, Professor Nielson Ribeiro and other coworkers of LADEBIO and LABTECH.

\section{REFERENCES}

Antal, M. J., Mok, W. S. L. and Richards, G. N., Mechanism of formation of 5-(hydroxymethyl)-2furaldehyde from d-fructose and sucrose. Carbohydr. Res., 199, 91-109 (1990).

Bicker, M., Hirth, J. and Vogel, H., Dehydration of fructose to 5-hydroxymethylfurfural in sub- and supercritical acetone. Green Chem., 5, 280-284 (2003).

Caes, B. R., Palteb, M. J. and Raines, R. T., Organocatalytic conversion of cellulose into a platform chemical. Chemical Science, 4, 196-199 (2013).

Combs, E., Cinlar, B., Pagan-Torres, Y., Dumesic, J. A. and Shanks, B. H., Influence of alkali and alkaline earth metal salts on glucose conversion to 5-hydroxymethylfurfural in an aqueous system. Cat. Comm., 30, 1-4 (2013).
Daorattanachai, P., Khemthong, P., Vriya-empikul, N., Laosiripojana, N. and Faungnawakij, K., Conversion of fructose, glucose, and cellulose to 5-hydroxymethylfurfural by alkaline earth phosphate catalysts in hot compressed water. Carbohyd. Res., 363, 58-61 (2012).

Huang, R., Qi W., Su, R. and He, Z., Integrating enzymatic and acid catalysis to convert glucose into 5-hydroxymethylfurfural. Chem. Commun., 46, 1115-1117 (2010).

Lecomte, J., Finiels, A. and Moreau, C., Kinetic study of the isomerization of glucose into fructose in the presence of anion-modified hydrotalcites. Starch/Stärke, 54, 75-79 (2002).

McNeff, C. V., Nowlan, D. T., McNeff, L. C., Yan, B. and Fefie, R. L., Continuous production of 5hydroxymethylfurfural from simple and complex carbohydrates. App. Catal., A, 384, 65-69 (2010).

Moliner, M., Roman-Leshkov, Y. and Davis, M., Tincontaining zeolites are highly active catalysts for the isomerization of glucose in water. Proc. Natl. Acad. Sci., 107, 6164-6168 (2010).

Moreau, C., Belgacem, M. N. and Gandini, A., Recent catalytic advances in the chemistry of substituted furans from carbohydrates and in the ensuing polymers. Top. Catal., 27(1-4), 11-30 (2004).

Nikolla, E., Román-Leshkov, Y., Moliner, M., Davis, M. E., "One-pot" synthesis of 5-(hydroxymethyl) furfural from carbohydrates using tin-beta zeolite. ACS Catal., 1, 408-410 (2011).

Peng, L., Lin, L. and Li, H., Extremely low sulfuric acid catalyst system for synthesis of methyl levulinate from glucose. Ind. Crops Prod., 40, 136144 (2012).

Peng, L., Lin, L., Zhang, J., Shia, J. and Liub, S., Solid acid catalyzed glucose conversion to ethyl levulinate. App. Catal., A, 397, 1-2, 259-265 (2011).

Pidko, E. A., Degirmenci, V., Santen, R. A. and Hensen, E. J. M., Glucose Activation by Transient $\mathrm{Cr}^{2+}$ Dimers. Angew. Chem. Int. Ed., 49, 25302534 (2010).

Putten, R.-J., Waal, J. C., Jong, E., Rasrendra, C. B., Heeres, H. J. and Vries, J. G., Hydroxymethylfurfural, a versatile platform chemical made from renewable resources. Chem. Reviews, 113, 14991597 (2013).

Qi, X., Watanabe, M., Aidaa, T. M., Smith Jr. R. L., Catalytic dehydration of fructose into 5-hydroxymethylfurfural by ion-exchange resin in mixedaqueous system by microwave heating. Green Chem., 10, 799-805 (2008).

Ranoux, A., Djanashvili, K., Arends, I. W. C. E., Hanefeld, U., 5-Hydroxymethylfurfural synthesis 
from hexoses is autocatalytic. ACS Catal., v. 3, 4, 760-763 (2013).

Rasrendra, C. B., Makertiharth, I. G., Adisasmito, S. and Heeres, H. J., Green chemicals from d-glucose: Systematic studies on catalytic effects of inorganic salts on the chemo-selectivity and yield in aqueous solutions. Top. Catal., 53, 1241-1247 (2010).

Ribeiro, M. L. and Schuchardt, U., Cooperative effect of cobalt acetylacetonate and silica in the catalytic cyclization and oxidation of fructose to 2,5-furandicarboxylic acid. Catal. Commun., 4, 83-86 (2003).

Román-Leshkov, Y. and Dumesic, J. A., Solvent effects on fructose dehydration to 5-hydroxymethylfurfural in biphasic systems saturated with inorganic salts. Top. Catal., 52, 297-303 (2009).

Román-Leshkov, Y., Barrett, C. J., Liu, Z. Y. and Dumesic, J. A., Production of dimethylfuran for liquid fuels from biomass-derived carbohydrates. Nature, 447, 982-986 (2007).

Rosatella, A. A., Simeonov, S. P., Frade, R. F. M. and Afonso, C. A. M., 5-Hydroxymethylfurfural (HMF) as a building block platform: Biological properties, synthesis and synthetic applications. Green Chem., 13, 754-793 (2011).
Shi, N., Liu, Q., Zhang, Q., Wang, T. and Ma L., High yield production of 5-hydroxymethylfurfural from cellulose by high concentration of sulfates in biphasic system. Green Chemistry, 15, 19671974 (2013).

Simeonov, A. P., Coelho, J. A. S., Afonso, C. A. M., Integrated chemo-enzymatic production of 5-hydroxymethylfurfural from glucose. ChemSusChem, 6, 997-1000 (2013).

Watanabe, M., Aizawa, Y., Lida, T. M., Ainda, T. M., Levy, C., Sue, K. and Inomata, H., Glucose reactions with acid and base catalysts in hot compressed water at 473 K. Carbohyd. Res., 340, 1925- (2005).

Yang, Y., Hua, C. and Abu-Omar, M. M., Conversion of glucose into furans in the presence of $\mathrm{AlCl}_{3}$ in an ethanol-water solvent system. Biores. Tech., 116, 190-194 (2012).

Zakrzewska, M. E., Bogel-Łukasik, E., Bogel-Łukasik, R., Ionic liquid-mediated formation of 5-hydroxymethylfurfuralsa promising biomass-derived building block. Chemical Reviews, 111, 397-417 (2011).

Zhang, Y., Du, H., Qian, X. and Chen, E.Y.-X., Ionic liquid-water mixtures: Enhanced $\mathrm{Kw}$ for efficient cellulosic biomass conversion. Energy Fuels, 24, 2410-2417 (2010). 